\title{
Transanal endoscopic microsurgery versus endoscopic mucosal resection for large rectal adenomas (TREND-study)
}

Frank JC van den Broek ${ }^{1}$, Eelco JR de Graaf ${ }^{2}$, Marcel GW Dijkgraaf3, Johannes B Reitsma ${ }^{3}$, Jelle Haringsma ${ }^{4}$, Robin Timmer ${ }^{5}$, Bas LAM Weusten ${ }^{5}$, Michael F Gerhards ${ }^{6}$, Esther CJ Consten ${ }^{7}$, Matthijs P Schwartz ${ }^{8}$, Maarten J Boom9, Erik J Derksen ${ }^{10}$, A Bart Bijnen ${ }^{11}$, Paul HP Davids ${ }^{12}$, Christiaan Hoff ${ }^{13}$, Hendrik M van Dullemen ${ }^{14}$, G Dimitri N Heine ${ }^{15}$, Klaas van der Linde ${ }^{16}$, Jeroen M Jansen ${ }^{17}$, Rosalie $\mathrm{CH}$ Mallant-Hent ${ }^{18}$, Ronald Breumelhof ${ }^{19}$, Han Geldof ${ }^{20}$, James CH Hardwick ${ }^{21}$, Pascal G Doornebosch ${ }^{22}$, Annekatrien CTM Depla ${ }^{23}$, Miranda F Ernst ${ }^{24}$, Ivo P van Munster ${ }^{25}$, Ignace HJT de Hingh ${ }^{26}$, Erik J Schoon 27, Willem A Bemelman ${ }^{28}$, Paul Fockens ${ }^{1}$ and Evelien Dekker*1

\begin{abstract}
Address: ${ }^{1}$ Dept of Gastroenterology \& Hepatology, Academic Medical Centre, Amsterdam, The Netherlands, ${ }^{2}$ Dept of Surgery, IJsselland Hospital, Capelle aan de IJssel, The Netherlands, ${ }^{3}$ Dept of Clinical Epidemiology, Biostatistics and bioinformatics, Academic Medical Centre, Amsterdam, The Netherlands, ${ }^{4}$ Dept of Gastroenterology, Erasmus Medical Centre, Rotterdam, The Netherlands, ${ }^{5}$ Dept of Gastroenterology, St Antonius Hospital, Nieuwegein, The Netherlands, ${ }^{6}$ Dept of Surgery, Onze Lieve Vrouwe Gasthuis, Amsterdam, The Netherlands, ${ }^{7}$ Dept of Surgery, Meander Medical Centre, Amersfoort, the Neterhlands, ${ }^{8}$ Dept of Gastroenterology, Meander Medical Centre, Amersfoort, the Neterhlands, ${ }^{9}$ Dept of Surgery, Flevoziekenhuis, Almere, The Netherlands, ${ }^{10}$ Dept of Surgery, Slotervaart Hospital, Amsterdam, The Netherlands, ${ }^{11}$ Dept of Surgery, Medical Centre Alkmaar, Alkmaar, The Netherlands, ${ }^{12}$ Dept of Surgery, Diakonessenhuis, Utrecht, The Netherlands, ${ }^{13}$ Dept of Surgery, Medical Centre Leeuwarden, Leeuwarden, The Netherlands, ${ }^{14}$ Dept of Gastroenterology, University Medical Centre, Groningen, The Netherlands, ${ }^{15}$ Dept of Gastroenterology, Medical Centre Alkmaar, Alkmaar, The Netherlands, ${ }^{16}$ Dept of Gastroenterology, Medical Centre Leeuwarden, Leeuwarden, The Netherlands, ${ }^{17}$ Dept of Gastroenterology, Onze Lieve Vrouwe Gasthuis, Amsterdam, The Netherlands, ${ }^{18}$ Dept of Gastroenterology,

Flevoziekenhuis, Almere, The Netherlands, ${ }^{19}$ Dept of Gastroenterology, Diakonessenhuis, Utrecht, The Netherlands, ${ }^{20}$ Dept of Gastroenterology, IJsselland Hospital, Capelle aan de IJssel, The Netherlands, ${ }^{21}$ Dept of Gastroenterology, Leiden University Medical Centre, Leiden, The Netherlands, ${ }^{22}$ Dept of Surgery, IJsselland Hospital, Capelle aan de IJssel, The Netherlands, ${ }^{23}$ Dept of Gastroenterology, Slotervaart Hospital, Amsterdam, The Netherlands, ${ }^{24}$ Dept of Surgery, Jeroen Bosch Hospital, 's-Hertogenbosch, The Netherlands, ${ }^{25}$ Dept of Gastroenterology, Jeroen Bosch Hospital, 's-Hertogenbosch, The Netherlands, 26Dept of Surgery, Catharina Hospital, Eindhoven, The Netherlands, 27Dept of Gastroenterology, Catharina Hospital, Eindhoven, The Netherlands and ${ }^{28}$ Dept of Surgery, Academic Medical Centre, Amsterdam, The Netherlands

Email: Frank JC van den Broek - f.j.vandenbroek@amc.uva.nl; Eelco JR de Graaf - edgraaf@ysl.nl;

Marcel GW Dijkgraaf - m.g.dijkgraaf@amc.uva.nl; Johannes B Reitsma - j.reitsma@amc.uva.nl; Jelle Haringsma - j.haringsma@erasmusmc.nl; Robin Timmer - r.timmer@antonius.net; Bas LAM Weusten - b.weusten@antonius.net; Michael F Gerhards - m.f.gerhards@olvg.nl; Esther CJ Consten - ecj.consten@meandermc.nl; Matthijs P Schwartz - mp.schwartz@meandermc.nl;

Maarten J Boom - mboom@flevoziekenhuis.nl; Erik J Derksen - ej.derksen@slz.nl; A Bart Bijnen - a.b.bijnen@mca.nl;

Paul HP Davids - pdavids@diakhuis.nl; Christiaan Hoff - c.hoff@znb.nl; Hendrik M van Dullemen - h.m.dullemen@int.umcg.nl; G Dimitri N Heine - g.d.n.heine@mca.nl; Klaas van der Linde - k.v.d.linde@znb.nl; Jeroen M Jansen - j.m.jansen@olvg.nl; Rosalie CH MallantHent - rmallant@flevoziekenhuis.nl; Ronald Breumelhof - rbreumelhof@diakhuis.nl; Han Geldof - han@hgeldof.nl;

James CH Hardwick - j.c.h.hardwick@lumc.nl; Pascal G Doornebosch - p.doornebosch@ysl.nl; Annekatrien CTM Depla - actm.depla@slz.nl; Miranda F Ernst - m.ernst@jbz.nl; Ivo P van Munster - i.v.munster@jbz.nl; Ignace HJT de Hingh - ignace.d.hingh@catharina-ziekenhuis.nl; Erik J Schoon - erik.schoon@catharina-ziekenhuis.nl; Willem A Bemelman - w.a.bemelman@amc.nl; Paul Fockens - p.fockens@amc.uva.nl; Evelien Dekker* - e.dekker@amc.uva.nl

* Corresponding author
\end{abstract}

Published: 13 March 2009

BMC Surgery 2009, 9:4 doi:10.1 186/147|-2482-9-4

This article is available from: http://www.biomedcentral.com/I47/-2482/9/4

(C) 2009 Broek et al; licensee BioMed Central Ltd.

This is an Open Access article distributed under the terms of the Creative Commons Attribution License (http://creativecommons.org/licenses/by/2.0), which permits unrestricted use, distribution, and reproduction in any medium, provided the original work is properly cited.
Received: 27 January 2009

Accepted: 13 March 2009 


\begin{abstract}
Background: Recent non-randomized studies suggest that extended endoscopic mucosal resection (EMR) is equally effective in removing large rectal adenomas as transanal endoscopic microsurgery (TEM). If equally effective, EMR might be a more cost-effective approach as this strategy does not require expensive equipment, general anesthesia and hospital admission. Furthermore, EMR appears to be associated with fewer complications.
\end{abstract}

The aim of this study is to compare the cost-effectiveness and cost-utility of TEM and EMR for the resection of large rectal adenomas.

Methods/design: Multicenter randomized trial among 15 hospitals in the Netherlands. Patients with a rectal adenoma $\geq 3 \mathrm{~cm}$, located between $\mathrm{I}-15 \mathrm{~cm}$ ab ano, will be randomized to a TEM- or EMR-treatment strategy. For TEM, patients will be treated under general anesthesia, adenomas will be dissected en-bloc by a full-thickness excision, and patients will be admitted to the hospital. For EMR, no or conscious sedation is used, lesions will be resected through the submucosal plane in a piecemeal fashion, and patients will be discharged from the hospital. Residual adenoma that is visible during the first surveillance endoscopy at 3 months will be removed endoscopically in both treatment strategies and is considered as part of the primary treatment.

Primary outcome measure is the proportion of patients with recurrence after 3 months. Secondary outcome measures are: 2) number of days not spent in hospital from initial treatment until 2 years afterwards; 3) major and minor morbidity; 4) disease specific and general quality of life; 5) anorectal function; 6) health care utilization and costs. A cost-effectiveness and cost-utility analysis of EMR against TEM for large rectal adenomas will be performed from a societal perspective with respectively the costs per recurrence free patient and the cost per quality adjusted life year as outcome measures.

Based on comparable recurrence rates for TEM and EMR of 3.3\% and considering an upper-limit of $10 \%$ for EMR to be non-inferior (beta-error 0.2 and one-sided alpha-error 0.05), 89 patients are needed per group.

Discussion: The TREND study is the first randomized trial evaluating whether TEM or EMR is more cost-effective for the treatment of large rectal adenomas.

Trial registration number: (trialregister.nl) NTRI422

\section{Background}

Rectal cancer is a common disease in the Netherlands with approximately 4,000 new cases and 2,000 deaths annually[1]. The incidence of rectal cancer increases with age, male sex and obesity, without ethnic preference [2-4]. In the pathogenesis, premalignant intraepithelial neoplasia that is located in a rectal adenoma, precedes the occurrence of invasive rectal cancer[5,6]. Early endoscopic detection and removal of rectal adenomas prevents the development of rectal cancer and is therefore the most reliable contributor to the 'cure' of this disease[7,8]. When rectal adenomas become large, however, standard endoscopic therapies like simple loop polypectomy or one-step endoscopic resection will be inadequate. Therefore, large rectal adenomas must be removed either surgically or by extended endoscopic mucosal resection (EMR)[9].

In 1984 a novel surgical approach for the resection of large rectal adenomas has been introduced in Germany: transanal endoscopic microsurgery (TEM)[10]. This pro- cedure encompasses general anesthesia, the use of expensive specialized equipment, a full-thickness rectal wall excision and hospital admission[11,12]. Since its introduction, many surgical practices (including the Netherlands) have adopted TEM as the new standard therapy for large rectal adenomas $[13,14]$. Alongside the introduction and refinement of TEM for rectal adenomas, advanced endoscopic therapies like extended EMR have rapidly evolved[15,16]. For extended EMR no sedation, no sophisticated equipment and no hospital admission are required as opposed to TEM[9]. Furthermore, only the neoplastic mucosa is resected instead of the full-thickness rectal wall, having a potential benefit of fewer complications.

Supporters of the TEM technique praise the excellent exposure of the rectum and the minimal invasiveness, as opposed to conventional surgical techniques [17-19]. Besides, recurrence rates after TEM appear to be lower when compared to conventional surgical transanal exci- 
sion[20]. The TEM technique has shown to be highly efficacious in several retrospective and prospective case series with reported recurrence rates of $0-19 \%$ and complication rates of $2-21 \%$ [21-41].

On the other hand, extended EMR has gained more and more support in the last few years, mainly due to good clinical results after EMR in the esophagus and stomach $[42,43]$. Endoscopic mucosal resection has also been described for the treatment of large colorectal adenomas, revealing recurrence rates of $0-9 \%$ and complication rates of only $0-9 \%$ [44-53]. In case adenomas can not be removed completely during one EMR attempt, repeat EMR for residual disease generally leads to an overall success rate of 96-100\%. Recently, the first prospective study analyzing extended EMR for large rectal adenomas has been described, revealing a recurrence rate of $8 \%$ and complication rate of $8 \%[9]$. In this study, all recurrences were detected during the first control endoscopy after 3 months; repeat EMR of residual disease led to an overall success rate of $98.4 \%$.

Since the efficacy of extended EMR for large rectal adenomas appears to be comparable to TEM, we started a prospective registration of patients with large nonpedunculated rectal adenomas who were treated by EMR in the Academic Medical Center Amsterdam. Preliminary results of this study were published in abstract form, demonstrating that EMR is safe and effective for the resection of large rectal adenomas having an overall success rate so far of $100 \%[54]$.

Until now, TEM and EMR have never been formally compared, and no such comparative studies have been registered at this moment. Although selection bias inevitably exists in prospective and retrospective case series, the results of these studies suggest that both TEM and EMR have comparable recurrence rates. Even when recurrences occur after TEM or EMR, most of these can successfully be re-treated without the need for radical surgery. The literature furthermore suggests that EMR is associated with fewer complications, reduced hospital admission, and no general anesthesia is required for EMR, all of which are favorable in both patients' and societal perspective. These contrasts of the two procedures might well lead to differences in costs and quality of life. Therefore, we designed a multicenter randomized trial to compare TEM and EMR for the resection of large rectal adenomas. The main objective of this study will be a cost-effectiveness and cost-utility analysis of these two procedures.

\section{Methods/Design Hypothesis}

Transanal endoscopic microsurgery and extended EMR are both effective treatments for large rectal adenomas with comparable recurrence rates. However, EMR does not require general/spinal anesthesia or hospital admission and may be associated with lower morbidity. Therefore, EMR may improve quality of life and reduce health care costs.

\section{Objective}

The main objective of the proposed randomized study is to compare the cost-effectiveness and cost-utility of TEM and EMR for the removal of large rectal adenomas. For a cost-effectiveness and cost-utility analysis the following study aims are taken into consideration:

- Comparison of recurrence rates after removal of large rectal adenomas by TEM or EMR.

- Comparison of morbidity and mortality associated with both procedures, by counting the number of patients with complications and the number of days that patients are alive, outside the hospital and without recurrence.

- Comparison of general and disease specific quality of life of patients before and after treatment by TEM or EMR.

- Comparison of health care service costs, production loss, and out-of-pocket expenses for TEM and EMR.

\section{Design}

This will be a multicenter randomized trial comparing TEM and EMR in patients with large rectal adenomas with respect to cost-effectiveness and safety (figure 1).

\section{Randomization}

Patient data are entered into a computerized database and by means of an unchangeable computer generated number patients will be randomized to undergo TEM or EMR. Randomization will be stratified by whether patients have a primary adenoma or residual/recurrent disease after prior resection.

\section{Blinding}

Blinding of patients and physicians during treatment is unfeasible, since the two treatment strategies are highly different in nature and in associated care. Endoscopic follow-up for recurrence, however, will be performed by independent endoscopists who are blinded for treatment strategy (see also primary outcome measure).

\section{Study population}

Patients are eligible for this trial when they meet the following inclusion criteria:

(1) Diagnosed with a large non-pedunculated rectal adenoma (sessile or flat) with a largest diameter of $\geq 3 \mathrm{~cm}$ (estimated by an opened biopsy forceps of $8 \mathrm{~mm}$ or an opened resection snare of 13,20 or $30 \mathrm{~mm}$ ). 


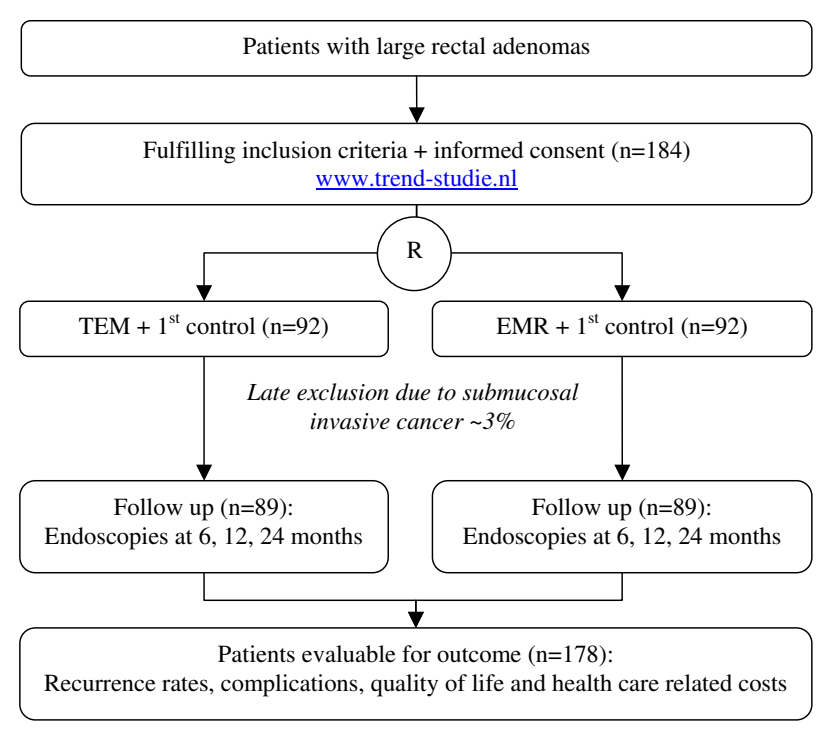

\section{Figure I \\ Flow chart of TREND study; I 5 Dutch centers will be participating in this multicenter randomized trial ( $R$ = randomization).}

(2) The lower border of the adenoma is located at $\geq 1 \mathrm{~cm}$ and $\leq 15 \mathrm{~cm}$ from the anal verge, respectively.

(3) Biopsies of the lesion, if taken, did not show invasion of neoplastic tissue in the submucosal layer on histopathological evaluation; only lesions with intraepithelial (low or high grade) or intramucosal neoplasia are suitable for inclusion.

(4) During flexible video endoscopy there are no signs of endoscopic suspicion for submucosal invasive cancer (Kudo pit pattern type V; excavated/depressed type morphology; fold convergence; or large smooth nodule $>1 \mathrm{~cm}$ in a flat lesion) $[55,56]$.

(5) In case of doubt, endoscopic ultrasonography (EUS) of the rectal adenoma should exclude invasion into the submucosal layer and exclude pathological lymphadenopathy (lymph nodes $>1 \mathrm{~cm}$ ). When pathological lymph nodes are present, fine needle aspiration will be performed to exclude lymph node metastasis.

(6) If not performed already, total colonoscopy will be done to detect and remove all synchronous colonic adenomas or cancers first. Cecal intubation must be confirmed by identification of the appendiceal orifice and ileocecal valve.

(7) The general health condition of the patient permits general/spinal anesthesia (ASA-classification I-III).
(8) Absence of non-correctable coagulopathy (international normalized ratio $>2$, or platelet count $<90 \times 10^{\%} / 1$ ).

(9) Patient age of 18 years or older.

\section{Participating centers}

Fifteen Dutch hospitals of the TREND-study group, including four academic and eleven non-academic centers, will enroll patients.

\section{Intervention strategies}

Transanal endoscopic microsurgery

TEM will be performed as described by Buess[12]. Under general/spinal anesthesia a specialized TEM rectoscope of 12 or $20 \mathrm{~cm}$ in length (Wolf GmbH Knittlingen or Storz GmbH Tuttlingen, Germany) is inserted within the rectum to assure proper visualization of the lesion. The rectoscope is fixed to the operating table by a supporting device, providing the opportunity to reposition the rectoscope during ongoing surgery. The rectal cavity is insufflated with $\mathrm{CO}_{2}$ by a combined endosurgical unit to achieve constant distension for appropriate visualization of the rectal adenoma. The combined endosurgical unit further regulates irrigation and suction, thereby maintaining a constant intra rectal pressure. With the use of a binocular stereoscopic eyepiece for three-dimensional view (Wolf GmbH only) or a forward oblique telescope (Storz $\mathrm{GmbH}$ ) a magnified view is being created for visualization of the lesion. With various instruments (multifunctional TEM400 (Erbe Elektromedizin GmbH, Tubingen, Germany), Ultracision harmonic scalpel (Ethicon EndoSurgery, Cincinnati, USA), needle diathermy, tissue handling forceps, needle holder, suction probe, injection needle, clip applicator) the adenoma will be dissected by means of an en-bloc full-thickness rectal wall excision until the perirectal fat. Postoperatively, patients will preserve a urinary catheter that will be removed at the first postoperative day. Patients are admitted to the hospital in accordance with current practice.

After 3 months a control flexible endoscopy will be performed. If presumed residual disease is seen, biopsies will be taken to confirm the presence of neoplasia by histology. Hereafter, the residual adenomatous tissue will be resected endoscopically by either EMR (if $>5 \mathrm{~mm}$ ) or argon plasma coagulation (APC) (if $<5 \mathrm{~mm}$ ). Any intervention by EMR/APC at 3 months is part of the TEM treatment strategy.

\section{Endoscopic mucosal resection}

Endoscopic mucosal resection is performed as described by Karita and Hurlstone[9,15]. At the discretion of the endoscopist, conscious sedation is used with $2.5-10 \mathrm{mg}$ midazolam and/or 25-100 $\mu \mathrm{g}$ of fentanyl. An endoscope 
(gastroscope or sigmoidoscope) is inserted into the rectum and air insufflation via the endoscope will provide proper distension of the rectum. The submucosa underneath the lesion will be injected through an endoscopic injection catheter with a solution of saline $0.9 \%, 1 \mathrm{ml}$ methylene blue, and 1:10,000 units adrenaline in order to lift the adenoma (no upper volume limit). A (barbed or standard) resection snare will be placed around a part of the lesion and subsequently tightened for resection through the submucosal layer by electro-coagulation. Each part of the adenoma will be resected by this piecemeal fashion until the entire lesion is macroscopically removed and the blue colored submucosa is visualized. Visible submucosal vessels will be treated by endoscopic clips or electro-coagulation to prevent delayed bleeding. Hereafter, the edges of the mucosal defect and potential remnants within the resection crater will always be treated with APC to increase adenoma clearance. If bleeding during the procedure precludes $100 \%$ clearance of the adenoma, the EMR procedure will be continued after 1 day until all adenomatous tissue is resected. In case of procedural blood loss of $>100 \mathrm{~mL}$ or if delayed perforation is anticipated on procedural grounds, patients are admitted to the hospital for observation; otherwise, they are discharged after the procedure in accordance with current practice.

After 3 months the treating endoscopist will perform a control endoscopy. If presumed residual disease is seen, biopsies will be taken to confirm the presence of neoplasia by histology. Hereafter, the residual adenomatous tissue will be resected endoscopically by either EMR (if $>5$ $\mathrm{mm}$ ) or APC (if $<5 \mathrm{~mm}$ ). Any intervention by EMR/APC at 3 months is part of the EMR treatment strategy.

\section{Informed consent procedure}

Consecutive eligible patients will be recruited at the outpatient clinic in the participating centers by the involved physician (surgeon or gastroenterologist). Patients fulfilling the abovementioned inclusion criteria will be informed about the study by the physician. After written informed consent, patients will be allocated to either TEM or EMR by computerized block randomization with variable block size via the study website http://www.trendstudie.nl. The patient will subsequently be scheduled for therapy in the participating centre. Patients unable or refusing to provide informed consent will be treated according to current clinical practice.

\section{Intervention failure}

When for technical reasons EMR procedures turn out not to be performable after randomization, the patient will automatically undergo the TEM treatment strategy. When TEM turns out not to be performable, an attempt with EMR will be done as well. When adenomas turn out to be too large or too high in the rectum for TEM by the Storz equipment, the patient will undergo TEM in another hospital where Wolf equipment is available.

\section{Safety monitoring}

In order to control for quality of the treatment (TEM or EMR) all procedures will be taped for reference. The first 3 procedures and an additional random sample per specialist will be assessed for quality by an expert panel at 2 time points during each year.

\section{Histopathological evaluation}

Resection specimens after TEM will be stretched and pinned on a cork plate before immersion into formalin. After standard processing the resection specimen will be transected each $\mathrm{cm}$ for evaluation by a gastrointestinal pathologist. The lateral and basal resection margins will be evaluated for absence of neoplasia, when possible. All resected pieces by EMR will be processed in the same manner, and only the basal resection margins will be evaluated.

The risk of lymph node metastases is increased in case of neoplasia extending into the submucosal layer, poor tumor differentiation, mucinous cancer, vascular invasion and tumor budding, all of which warrant further radical surgery [57-60]. By strict adherence to the inclusion criteria, the risk of invasive cancer is reduced to 1.6$3 \%[56,61]$. In case of an unexpected invasive cancer despite adherence to the inclusion criteria, the patient will be excluded after the histopathological evaluation (late exclusion). In case of intramucosal cancer (i.e. not invading through the muscularis mucosae), both TEM and EMR will be regarded as sufficient treatment when the lesion is radically removed.

\section{Outcome parameters}

\section{Primary outcome measure (for non-inferiority)}

(1) Recurrence of neoplasia, defined as the presence of histologically proven neoplastic tissue in either visible recurrent lesions or in random biopsies, taken at surveillance endoscopies after the intervention strategy has been completed.

Any remnant adenoma identified and treated by EMR/ APC at 3 months is considered part of the initial intervention strategy in both arms. Hereafter, patients will undergo surveillance endoscopies (with a GIF-Q160 endoscope) at 6, 12 and 24 months by an independent endoscopist who is blinded for the primary treatment. During each surveillance endoscopy recurrence will objectively be defined by the Higaki criteria for recurrence: tumor appearing within a clear resection scar; tumors with convergent folds; and tumors nearby a clear resection scar (within $5 \mathrm{~mm}$ )[49]. Targeted biopsies will be taken for 
histological confirmation; in case of an apparently healed normal scar without evidence of recurrence, 3 biopsies will be taken from the basis and 3 from the edges of the scar to detect occult recurrent neoplasia.

(2) Since equal recurrence rates for the TEM and EMR strategies are anticipated (equivalence trial), an additional outcome measure has been chosen that is responsive to both differences in initial care and to additional procedures that may be required in both strategies: the number of days that a patient is alive, outside the hospital and free of recurrence during two-year follow-up starting at the day of the initial treatment. Every patient therefore has potentially 730 days, and hospital days will be subtracted for initial treatment, readmissions, re-interventions and surveillance endoscopies. Adenoma recurrence or death will be considered as failure of the treatment strategy and no more additional days outside the hospital will be counted for such a patient.

'Unrelated' readmissions may have a relatively large impact on the number of days outside the hospital as well as on costs in this equivalence trial, if by chance they are unevenly distributed among treatment arms. Therefore, we will exclude the unrelated readmissions in a subsequent sensitivity analysis (both clinically and during the cost-effectiveness and cost-utility analyses), meaning that days in hospital due to clearly unrelated causes will not be subtracted from the total number of potential days outside the hospital for a patient. Likewise, other unrelated health care or unrelated days of sick leave will be excluded in this sensitivity analysis. Whether readmissions are related or unrelated to the target condition will be assessed by an independent expert panel (blinded for treatment).

The following standardized discharge criteria will be applied in all participating hospitals: normal intake of nutrition; normal mobility; absence of fever $\left(<38^{\circ} \mathrm{C}\right)$; and stable hemoglobin level during 1 day $(<1 \mathrm{mmol} / \mathrm{L})$ in case of rectal blood loss.

\section{Additional outcome measures}

(a) Complications: subdivided into procedural (during treatment) and delayed complications (after ending the procedure); and further subdivided into major (requiring additional surgery) and minor (requiring endoscopic or medical intervention) complications.

During admission patients will be monitored for complications. In case of same day discharge from the hospital patients will be called by telephone 1 day after the procedure whether adverse events have happened. Two weeks after the intervention, a research nurse will contact the patient by telephone again and ask for occurred complications.

(b) Generic and disease-specific health related quality of life will be measured at baseline, 2 weeks, 3 months, 6 months, 1 year and 2 year follow-up by the EQ-5D, SF-36, Wexner score (for incontinence) and COREFO questionnaires[62].

(c) Costs of TEM and EMR from a societal perspective, based on primary data (see economic evaluation section).

(d) Patient preferences regarding TEM or EMR will be measured at the end of follow-up by a structured questionnaire to enable a discrete choice experiment addressing the burden of care, burden of complications, prognostic uncertainties, and recurrence rates of both treatments.

\section{Sample size calculation}

Assuming a baseline recurrence rate of 3.3\% for both TEM and EMR (average recurrence based on a systematic review) and considering an upper limit of $10 \%$ for EMR to be non-inferior, with a $\beta$-error of 0.2 and $\alpha$-error of 0.05 , 89 patients are needed per randomization group. As unexpected invasive cancers are expected in maximally $3 \%$ of patients, the total sample size will be 184 patients.

Since EMR is known to be effective in even more than 2 attempts, an upper limit of $10 \%$ seems reasonable, whereas higher recurrence rates would lead to many additional procedures which renders this strategy impracticable and probably not cost-effective.

\section{Ethics}

This study is conducted in accordance with the principles of the Declaration of Helsinki and 'good clinical practice' guidelines. The medical ethical committee of the Academic Medical Centre Amsterdam has approved the study protocol (MEC number 08/183 \# 08.17.1104). Prior to randomization, written informed consent will be obtained from all patients.

\section{Data-analysis}

Since the main outcome of this study is the neoplasia recurrence rate, i.e. proportion of patients with recurrent disease, the Chi-square test will be used to compare the intervention groups (TEM versus EMR). Since the event of recurrence, and not time to recurrence, is the most important indicator for treatment failure, Kaplan Meier methods will not be used. The complication and mortality rates will be compared in the same manner. The number of days not spent in hospital as additional primary outcome measure will be compared by the Wilcoxon rank sum test. 
Differences between the intervention groups in continuous outcome measures (e.g. Wexner incontinence scale, quality of life questionnaires) will be tested by the student's t-test or Wilcoxon rank sum test, where appropriate.

All analyses will be carried out primarily on an intentionto-treat basis.

\section{Economic evaluation}

\section{General considerations}

The economic evaluation of EMR against TEM for large rectal adenomas will be performed as a cost-effectiveness analysis as well as a cost-utility analysis from a societal perspective. The primary outcomes are the costs per recurrence free patient and the costs per quality adjusted life year respectively. The costs per patient free of complications as well as the costs per day alive and outside the hospital will be considered as secondary outcome. The time horizon is restricted to a follow-up of 24 months. Given this time span, discounting (of costs and effects) will be performed. Incremental cost-effectiveness ratios are calculated, reflecting the extra costs per additional recurrence free patient and the extra costs per additional QALY. Sensitivity analyses will be performed to account for sampling variability (following bias corrected and accelerated nonparametric bootstrapping), for plausible ranges in unit costs of surgery and endoscopic treatment, for (differential) discount rates of costs and effects, and for different health utility algorithms (see below). Subgroup analyses will be performed for patients with different rectal adenoma diameters $(<5 \mathrm{~cm}, 5-10 \mathrm{~cm},>10 \mathrm{~cm})$ and distances of the adenoma from the anal verge $(<7.5 \mathrm{~cm}$ versus $7.5-15 \mathrm{~cm}$ ) in order to tentatively assess differences in health care efficiency.

In case TEM and EMR turn out clinically equivalent, the study will be performed as a cost-minimization analy$\operatorname{sis}[63]$.

\section{Cost analysis}

The evaluation will include the direct medical costs, outof-pocket expenses, and the indirect non-medical costs of production loss. The direct medical costs will include the costs of all diagnostic procedures (except study-related ones like anal manometry), therapeutic (repeat) interventions, medication, admissions, day care treatments, specialist consultations, and out-of-hospital care (like general physician, fecal incontinence pads, etc) during follow-up. With approximately over $40 \%$ of patients below 65 years of age, production losses will be estimated and based on questionnaire data concerning absence from work and lower efficiency while at work. Out-of-pocket expenses will include the costs of health-related travel, over-thecounter medication, extra washing, etc. Volume data will be gathered with clinical report forms, available hospital information systems, and the Dutch Health and Labour Questionnaire (to be completed by patients at baseline, week 2, and months 3,12, and 24). The Dutch costing guideline for health care research will be used to determine the relevant unit costs. In case of the TEM and EMR however, micro-costing (general/spinal/conscious anesthesia or sedation, surgical and endoscopic equipment, procedure duration, involved personnel, overhead) in participating centers will be done to estimate real unit costs. The friction costs method will be applied to derive the costs of lost productivity. After price-indexing all costs will be expressed in 2009 euros.

\section{Patient outcome analysis}

Patients' health status and quality of life will be assessed with the Wexner score, COREFO and SF-36. In addition, the EQ-5D questionnaire is used to generate health status scoring profiles over time, which will subsequently be translated in QALYs by applying time trade-off based health utility algorithms $[64,65]$ (see also the sensitivity analyses above) and assuming that a health utility score at any point in time best reflects a patients health status inbetween the actual and the previous measurement. In addition, patient preferences regarding TEM and EMR will be measured at the end of follow-up by a structured questionnaire to enable a discrete choice experiment addressing the burden of care, burden of complications, prognostic uncertainties, and recurrence rates of both treatments[66].

\section{Discussion}

Colorectal cancer (CRC) is the second most common cancer in the Netherlands with 9,989 new cases and 4,429 deaths in the year 2003[1]. Rectal cancer accounts for approximately $40 \%$ of those CRC cases. The treatment of rectal cancer encompasses a multidisciplinary collaboration including gastroenterologists, surgeons, oncologists, radiotherapists and specialized nurse practitioners. Standard therapy consists of radical surgery in combination with radiotherapy (and possibly chemotherapy), which have major morbidity and mortality[67]. Therefore, this disease has a major impact on health care services[68]. Since early detection and removal of rectal adenomas prevents the occurrence of rectal cancer, CRC screening has been adopted in many western countries[69]. In the Netherlands a pilot study for CRC screening, based on fecal occult blood testing, has been performed (ZonMw funded)[70]. When CRC screening is introduced in the Netherlands, this will inevitably lead to an increased detection of early rectal neoplasia[71]. It is therefore expected that more rectal adenomas will need endoscopic or surgical treatment in the forthcoming years. Consequently, the most appropriate therapy concerning efficacy, safety, quality of life and costs must be selected to deal with the expected increase in rectal adenomas. 
Traditionally, adenomatous colorectal lesions that could not be resected endoscopically were referred for surgery. Conventional surgical approaches like radical surgery and trans-sphincteric or trans-sacral operations have nowadays been replaced by TEM, since this procedure has higher efficacy and lower morbidity [18-20]. However, no improvement in quality of life could be encountered by TEM, when compared to conventional radical surgery[17]. In recent years endoscopic therapies have further evolved, as a result of which large rectal adenomas more often are treated endoscopically, at the expense of TEM[9]. In case series, endoscopic resection of large colorectal adenomas has led to recurrence rates that were comparable to TEM (2.0\% vs. $3.6 \%$ respectively), and complication rates that appeared lower $(4.4 \%$ vs. $10.7 \%)[9,22,23,26,27,29$ 31,34-37,41,45,48,49,52,53,72-74]. Furthermore, EMR can safely be performed without sedation, or with conscious sedation only, and generally no hospital admission is required as opposed to TEM. The reduced morbidity, reduced hospital admission and redundancy of anesthesia associated with EMR are beneficial from both patients' and societal perspective.

Nevertheless, current clinical practice concerning the treatment of large rectal adenomas mainly depends on experience with TEM or EMR in various hospitals and on the clinical judgment of the involved physician instead of on evidence, which is lacking with reference to the treatment of large rectal adenomas. Although the literature suggests that TEM and EMR are equivalent techniques concerning efficacy and that EMR appears favorable concerning morbidity, a formal comparison of cost-effectiveness and cost-utility has never been performed and no ongoing studies comparing these two techniques have been registered in trial-registers so far.

\section{Abbreviations}

TREND: TRansanal ENDoscopic microsurgery versus endoscopic mucosal resection for large rectal adenomas; TEM: transanal endoscopic microsurgery; EMR: endoscopic mucosal resection; EUS: endoscopic ultrasonography; ASA: American Society of Anaesthesiologists; APC: argon plasma coagulation; EQ-5D: Euroqol 5 Dimensions; SF-36: short form-36; COREFO: COloREctal Functional Outcome questionnaire.

\section{Competing interests}

The authors declare that they have no competing interests.

\section{Authors' contributions}

FvdB, EdG, MD, JR, WB, PF, ED have made substantial contributions to the conception and design of this study; have been involved in drafting the manuscript (FvdB) or revising it critically for important intellectual content
(EdG, MD, JR, WB, PF, ED); and have given final approval of the version to be published.

JH, RT, BW, MG, EC, MS, MB, ED, AB, PD, CH, HvD, GH, KvdL, JJ, RM-H, RB, HG, JH, PD, AD, ME, IvM, IdH, ES have made contributions to the design of this study and have made substantial contributions to the organization of this trial in several meetings; have given final approval of the version to be published; and are local investigators at the participating centers.

\section{Acknowledgements}

This study is funded by ZonMw, project number I7099.220I

F.J.C. van den Broek is supported by an unrestricted educational grant from Olympus Medical Systems, Hamburg, Germany.

Paul Fockens has received a research grant from Olympus Medical Systems, Tokyo, Japan.

All authors are member of the TREND-study group.

\section{References}

I. Siesling S, Visser O, van Dijck JA, Coebergh JW: [Trends in the incidence and death from cancer from 1989-2003 in The Netherlands]. Ned Tijdschr Geneeskd 2006, I 50:2490-2496.

2. Regula J, Rupinski M, Kraszewska E, Polkowski M, Pachlewski J, Orlowska J, et al.: Colonoscopy in colorectal-cancer screening for detection of advanced neoplasia. N Engl J Med 2006, 355:1863-1872.

3. Jacobs ET, Martinez ME, Alberts DS, Jiang R, Lance P, Lowe KA, et al:: Association between body size and colorectal adenoma recurrence. Clin Gastroenterol Hepatol 2007, 5:982-990.

4. Rajendra S, Ho JJ, Arokiasamy J: Risk of colorectal adenomas in a multiethnic Asian patient population: race does not matter. J Gastroenterol Hepatol 2005, 20:5I-55.

5. Muto T, Nagawa H, Watanabe T, Masaki T, Sawada T: Colorectal carcinogenesis: historical review. Dis Colon Rectum 1997, 40:S80-S85.

6. Allen Jl: Molecular biology of colon polyps and colon cancer. Semin Surg Oncol 1995, I I:399-405.

7. Winawer SJ, Zauber AG, Ho MN, O'Brien MJ, Gottlieb LS, Sternberg SS, et al: Prevention of colorectal cancer by colonoscopic polypectomy. The National Polyp Study Workgroup. $N$ Engl J Med 1993, 329:1977-1981.

8. Zheng S, Liu XY, Ding KF, Wang LB, Qiu PL, Ding XF, et al.: Reduction of the incidence and mortality of rectal cancer by polypectomy: a prospective cohort study in Haining County. World J Gastroenterol 2002, 8:488-492.

9. Hurlstone DP, Sanders DS, Cross SS, George R, Shorthouse AJ, Brown S: A prospective analysis of extended endoscopic mucosal resection for large rectal villous adenomas: an alternative technique to transanal endoscopic microsurgery. Colorectal Dis 2005, 7:339-344.

10. Buess G, Hutterer F, Theiss ], Bobel M, Isselhard W, Pichlmaier H: [A system for a transanal endoscopic rectum operation]. Chirurg 1984, 55:677-680.

II. Saclarides TJ, Smith L, Ko ST, Orkin B, Buess G: Transanal endoscopic microsurgery. Dis Colon Rectum 1992, 35: I 183-I I9I.

12. Buess G, Kipfmuller K, Hack D, Grussner R, Heintz A, Junginger T: Technique of transanal endoscopic microsurgery. Surg Endosc 1988, 2:7|-75.

13. Saclarides TJ: TEM/local excision: Indications, techniques, outcomes, and the future. J Surg Oncol 2007, 96:644-650.

14. de Graaf Ej: Transanal endoscopic microsurgery. Scand J Gastroenterol Suppl 2003:34-39.

15. Karita M, Tada M, Okita K, Kodama T: Endoscopic therapy for early colon cancer: the strip biopsy resection technique. Gastrointest Endosc 1991, 37: 128-132. 
16. Kudo S, Tamegai Y, Yamano H, Imai Y, Kogure E, Kashida H: Endoscopic mucosal resection of the colon: the Japanese technique. Gastrointest Endosc Clin N Am 200 I, I I:5 I 9-535.

17. Doornebosch PG, Tollenaar RA, Gosselink MP, Stassen LP, Dijkhuis CM, Schouten WR, et al.: Quality of life after transanal endoscopic microsurgery and total mesorectal excision in early rectal cancer. Colorectal Dis 2007, 9:553-558.

18. Lin GL, Meng WC, Lau PY, Qiu HZ, Yip AW: Local resection for early rectal tumours: Comparative study of transanal endoscopic microsurgery (TEM) versus posterior trans-sphincteric approach (Mason's operation). Asian J Surg 2006 29:227-232.

19. Winde G, Nottberg H, Keller R, Schmid KW, Bunte H: Surgical cure for early rectal carcinomas (TI). Transanal endoscopic microsurgery vs. anterior resection. Dis Colon Rectum 1996, 39:969-976

20. Middleton PF, Sutherland LM, Maddern G]: Transanal endoscopic microsurgery: a systematic review. Dis Colon Rectum 2005 48:270-284.

21. Bretagnol F, Merrie A, George B, Warren BF, Mortensen NJ: Loca excision of rectal tumours by transanal endoscopic microsurgery. $B r$ J Surg 2007, 94:627-633.

22. Schafer $\mathrm{H}$, Baldus $\mathrm{SE}, \mathrm{Holscher} \mathrm{AH}$ : Giant adenomas of the rectum: complete resection by transanal endoscopic microsurgery (TEM). Int J Colorectal Dis 2006, 21:533-537.

23. Guerrieri M, Baldarelli M, Morino M, Trompetto M, Da RA, Selmi I, et al.: Transanal endoscopic microsurgery in rectal adenomas: experience of six Italian centres. Dig Liver Dis 2006, 38:202-207.

24. McCloud JM, Waymont N, Pahwa N, Varghese P, Richards C, Jameson JS, et al: Factors predicting early recurrence after transanal endoscopic microsurgery excision for rectal adenoma. Colorectal Dis 2006, 8:581-585.

25. Whitehouse PA, Tilney HS, Armitage JN, Simson JN: Transanal endoscopic microsurgery: risk factors for local recurrence of benign rectal adenomas. Colorectal Dis 2006, 8:795-799.

26. Mihai R, Borley N: Transanal endoscopic microsurgery impact on the practice of a colorectal surgeon in a district general hospital. Ann R Coll Surg Engl 2005, 87:432-436.

27. Rokke O, Iversen KB, Ovrebo K, Maartmann-Moe H, Skarstein A Halvorsen JF: Local resection of rectal tumors by transanal endoscopic microsurgery: experience with the first $\mathbf{7 0}$ cases. Dig Surg 2005, 22:182-189.

28. Ayodeji ID, Hop WC, Tetteroo GW, Bonjer HJ, de Graaf EJ: Ultracision Harmonic Scalpel and multifunctional tem 400 instrument complement in transanal endoscopic microsurgery: prospective study. Surg Endosc 2004, I 8: I730-1737

29. Katti G: An evaluation of transanal endoscopic microsurgery for rectal adenoma and carcinoma. JSLS 2004, 8: | 23- I 26.

30. Meng WC, Lau PY, Yip AW: Treatment of early rectal tumours by transanal endoscopic microsurgery in Hong Kong: prospective study. Hong Kong Med ] 2004, I 0:239-243.

31. Cocilovo C, Smith LE, Stahl T, Douglas J: Transanal endoscopic excision of rectal adenomas. Surg Endosc 2003, I7:|46|-|463.

32. Neary P, Makin GB, White TJ, White E, Hartley J, MacDonald A, Lee PW, Monson JR: Transanal endoscopic microsurgery: a viable operative alternative in selected patients with rectal lesions. Ann Surg Oncol 2003, 10: I 106-IIII.

33. Langer C, Liersch T, Markus P, Süss M, Ghadimi M, Füzesi L, Becker $\mathrm{H}$ : Transanal endoscopic microsurgery (TEM) for minimally invasive resection of rectal adenomas and "Low-risk" carcinomas (uTI, G I - 2). Z Gastroenterol 2002, 40:67-72.

34. Ramirez JM, Aguilella $V$, Arribas $D$, Martinez $M$ : Transanal fullthickness excision of rectal tumours: should the defect be sutured? a randomized controlled trial. Colorectal Dis 2002, 4:5I-55.

35. Lev-Chelouche D, Margel D, Goldman G, Rabau MJ: Transanal endoscopic microsurgery: experience with 75 rectal neoplasms. Dis Colon Rectum 2000, 43:662-667

36. Doornebosch PG, Tetteroo GW, Geldof H, de Graaf E]: [Transanal endoscopic microsurgery: a good choice for local resection of rectal tumors]. Ned Tijdschr Geneeskd 1998, I 42:2577-258I.

37. Spalinger $R$, Schlumpf $R$, Largiader $F$ : [Transanal endoscopic microsurgery - experiences at the Zurich University Hospital]. Schweiz Rundsch Med Prax 1998, 87:1014-1018.

38. Mentges B, Buess G, Schafer D, Manncke K, Becker HD: Local therapy of rectal tumors. Dis Colon Rectum 1996, 39:886-892.
39. Said S, Stippel D: Transanal endoscopic microsurgery in large, sessile adenomas of the rectum. A I0-year experience. Surg Endosc 1995, 9: I I06-III2.

40. Stipa S, Lucandri G, Stipa F, Chiavellati L, Sapienza P: Local excision of rectal tumours with transanal endoscopic microsurgery. Tumori 1995, 81:50-56.

4I. Khanduja KS: Transanal endoscopic microsurgery. Results of the initial ten cases. Surg Endosc 1995, 9:56-60.

42. Wang YP, Bennett C, Pan T: Endoscopic mucosal resection for early gastric cancer. Cochrane Database Syst Rev 2006:CD004276.

43. Ell C, May A, Gossner L, Pech O, Günter E, Mayer G, Henrich R, Vieth M, Müller H, Seitz G, et al:: Endoscopic mucosal resection of early cancer and high-grade dysplasia in Barrett's esophagus. Gastroenterology 2000, I I 8:670-677.

44. Bories E, Pesenti C, Monges G, Lelong B, Moutardier V, Delpero JR Giovannini M: Endoscopic mucosal resection for advanced sessile adenoma and early-stage colorectal carcinoma. Endoscopy 2006, 38:231-235.

45. Katsinelos P, Kountouras J, Paroutoglou G, Zavos C, Rizos C, Beltsis $A$ : Endoscopic mucosal resection of large sessile colorectal polyps with submucosal injection of hypertonic $\mathbf{5 0}$ percent dextrose-epinephrine solution. Dis Colon Rectum 2006 49: I384- 1392.

46. Hurlstone DP, Sanders DS, Thomson M, Cross SS: "Salvage" endoscopic mucosal resection in the colon using a retroflexion gastroscope dissection technique: a prospective analysis. Endoscopy 2006, 38:902-906

47. Kume K, Murata I, Yoshikawa I, Yamasaki M, Kanda K, Otsuki M: Endoscopic piecemeal mucosal resection of large colorectal tumors. Hepatogastroenterology 2005, 52:429-432.

48. Hurlstone DP, Sanders DS, Cross SS, Adam I, Shorthouse AJ, Brown S, Drew K, Lobo AJ: Colonoscopic resection of lateral spreading tumours: a prospective analysis of endoscopic mucosal resection. Gut 2004, 53:1334-1339.

49. Higaki S, Hashimoto S, Harada K, Nohara H, Saito Y, Gondo T, Okita $\mathrm{K}$ : Long-term follow-up of large flat colorectal tumors resected endoscopically. Endoscopy 2003, 35:845-849.

50. Brooker JC, Saunders BP, Shah SG, Thapar CJ, Suzuki N, Williams CB: Treatment with argon plasma coagulation reduces recurrence after piecemeal resection of large sessile colonic polyps: a randomized trial and recommendations. Gastrointest Endosc 2002, 55:37l-375.

5I. Tanaka S, Haruma K, Oka S, Takahashi R, Kunihiro M, Kitadai Y Yoshihara M, Shimamoto F, Chayama K: Clinicopathologic features and endoscopic treatment of superficially spreading colorectal neoplasms larger than $20 \mathbf{~ m m}$. Gastrointest Endosc 200I, 54:62-66.

52. lishi H, Tatsuta M, Kitamura S, Narahara H, Iseki K, Ishiguro S: Endoscopic resection of large sessile colorectal polyps using a submucosal saline injection technique. Hepatogastroenterology 1997 , 44:698-702.

53. Kanamori T, Itoh M, Yokoyama Y, Tsuchida K: Injection-incision assisted snare resection of large sessile colorectal polyps. Gastrointest Endosc 1996, 43:189-195.

54. Broek F van den, Fockens P, Dekker E: Prospective evaluation of extended endoscopic mucosal resection for large rectal adenomas. Gastroenterology 2008, I34:AI63.

55. Kudo S, Rubio CA, Teixeira CR, Kashida H, Kogure E: Pit pattern in colorectal neoplasia: endoscopic magnifying view. Endoscopy 200I, 33:367-373

56. Kobayashi N, Saito Y, Sano Y, Uragami N, Michita T, Nasu J, Matsuda T, Fu KI, Fujii T, Fujimori T, Ishikawa T, et al.: Determining the treatment strategy for colorectal neoplastic lesions: endoscopic assessment or the non-lifting sign for diagnosing invasion depth? Endoscopy 2007, 39:70I-705

57. Okabe S, Shia J, Nash G, Wong WD, Guillem JG, Weiser MR, Temple L, Sugihara K, Paty PB: Lymph node metastasis in TI adenocarcinoma of the colon and rectum. J Gastrointest Surg 2004, 8:1032-1039.

58. Nascimbeni R, Burgart LJ, Nivatvongs S, Larson DR: Risk of lymph node metastasis in $\mathrm{TI}$ carcinoma of the colon and rectum. Dis Colon Rectum 2002, 45:200-206.

59. Sakuragi M, Togashi K, Konishi F, Koinuma K, Kawamura Y, Okada M, Nagai $H$ : Predictive factors for lymph node metastasis in $\mathrm{T}$ I stage colorectal carcinomas. Dis Colon Rectum 2003, 46:1626-1632. 
60. Wang HS, Liang WY, Lin TC, Chen WS, Jiang JK, Yang SH, Chang SC, Lin JK: Curative resection of T I colorectal carcinoma: risk of lymph node metastasis and long-term prognosis. Dis Colon Rectum 2005, 48: I |82-I I 92.

61. Doornebosch PG, Bronkhorst PJ, Hop WC, Bode WA, Sing AK, de Graaf E): The Role of Endorectal Ultrasound in Therapeutic Decision-Making for Local vs. Transabdominal Resection of Rectal Tumors. Dis Colon Rectum 2008, 5 I:38-42.

62. Bakx R, Sprangers MA, Oort FJ, van Tets WF, Bemelman WA, Slors JF, van Lanschot J]: Development and validation of a colorectal functional outcome questionnaire. Int J Colorectal Dis 2005, 20:126-136.

63. Briggs $\mathrm{AH}, \mathrm{O}$ 'Brien $\mathrm{BJ}$ : The death of cost-minimization analysis? Health Econ 200I, 10:179-184.

64. Dolan P: Modeling valuations for EuroQol health states. Med Care 1997, 35: 1095-II08.

65. Lamers LM, Stalmeier PF, McDonnell J, Krabbe PF, van Busschbach J]: [Measuring the quality of life in economic evaluations: the Dutch EQ-5D tariff]. Ned Tijdschr Geneeskd 2005, 149: I 574-1578.

66. Ryan M: Discrete choice experiments in health care. BMJ 2004, 328:360-36I.

67. Peeters KC, Velde CJ van de, Leer JW, Martijn H, Junggeburt JM, Kranenbarg EK, Steup WH, Wiggers T, Rutten HJ, Marijnen CA: Late side effects of short-course preoperative radiotherapy combined with total mesorectal excision for rectal cancer: increased bowel dysfunction in irradiated patients - a Dutch colorectal cancer group study. J Clin Oncol 2005, 23:6199-6206.

68. Brink M Van Den, Hout WB Van Den, Stiggelbout AM, Klein Kranenbarg E, Marijnen CA, Velde CJ Van De, Kievit J, Dutch Colorectal Cancer Group: Cost-utility analysis of preoperative radiotherapy in patients with rectal cancer undergoing total mesorectal excision: a study of the Dutch Colorectal Cancer Group. J Clin Oncol 2004, 22:244-253.

69. Winawer S, Fletcher R, Rex D, Bond J, Burt R, Ferrucci J, Ganiats T, Levin $T$, Woolf $S$, Johnson $D$, et al:: Colorectal cancer screening and surveillance: clinical guidelines and rationale-Update based on new evidence. Gastroenterology 2003, I 24:544-560.

70. van Rijn AF, Dekker E, Kleibuker JH: [Screening the population for colorectal cancer: the background to a number of pilot studies in the Netherlands]. Ned Tijdschr Geneeskd 2006, 150:2739-2744.

71. de Visser M, van Ballegooijen M, Bloemers SM, van Deventer SJ, Jansen JB, Jespersen J, Kluft C, Meijer GA, Stoker J, de Valk GA, et al.: Report on the Dutch consensus development meeting for implementation and further development of population screening for colorectal cancer based on FOBT. Cell Oncol 2005, 27: 17-29.

72. Brooker JC, Saunders BP, Shah SG, Thapar CJ, Suzuki N, Williams CB: Treatment with argon plasma coagulation reduces recurrence after piecemeal resection of large sessile colonic polyps: a randomized trial and recommendations. Gastrointest Endosc 2002, 55:37I-375.

73. Hurlstone DP, Sanders DS, Thomson M, Cross SS: "Salvage" endoscopic mucosal resection in the colon using a retroflexion gastroscope dissection technique: a prospective analysis. Endoscopy 2006, 38:902-906.

74. Stipa S, Lucandri G, Stipa F, Chiavellati L, Sapienza P: Local excision of rectal tumours with transanal endoscopic microsurgery. Tumori 1995, 81:50-56.

\section{Pre-publication history}

The pre-publication history for this paper can be accessed here:

http://www.biomedcentral.com/1471-2482/9/4/prepub
Publish with Biomed Central and every scientist can read your work free of charge

"BioMed Central will be the most significant development for disseminating the results of biomedical research in our lifetime. "

Sir Paul Nurse, Cancer Research UK

Your research papers will be:

- available free of charge to the entire biomedical community

- peer reviewed and published immediately upon acceptance

- cited in PubMed and archived on PubMed Central

- yours - you keep the copyright

Submit your manuscript here:

http://www.biomedcentral.com/info/publishing_adv.asp
BioMedcentral 